\title{
Cowden syndrome is a risk factor for multiple neoplasm: a case report
}

\author{
Sofia Miguelote ${ }^{1 *}$ (D, Roberto Silva ${ }^{2,3}$, J. L. Fougo ${ }^{2,4}$, L. E. Barbosa ${ }^{1,2,5}$ and J. P. Araújo Teixeira ${ }^{1,2,5}$
}

\begin{abstract}
Background: Cowden's syndrome is an autosomal dominant disease with variable penetrance, involving the tumor suppressor phosphatase and tension homolog gene, located on chromosome 10q22-23, responsible for cell proliferation, migration, and cellular apoptosis. Its clinical presentation encompasses mucocutaneous lesions, which are present around 99\% of the time; macrocephaly; and cognitive impairment, and it precedes the appearance of neoplasms such as thyroid carcinoma, breast cancer, among others.

In addition to these malformations, arteriovenous malformations of the brain and spine, endocrine abnormalities, skeletal defects, and cardiopulmonary lesions may also be found.

The relevance of the case is due to the fact that, through a certain phenotype, the patient's genotype can be inferred and thus followed up closely.

Case representation: The clinical case concerns a 28-year-old Caucasian and Portuguese woman with palmar pits, macrocephaly, and cognitive impairment. She was diagnosed with papillary thyroid carcinoma at 22 years of age and proposed total thyroidectomy.

At age 27, a pregnancy was diagnosed with a Breast Imaging-Reporting and Data System 2-rated breast lump. After the histological verification, it was concluded that it was a high metastatic breast sarcoma, opting for palliative mastectomy. A genetic evaluation confirmed alteration in the phosphatase and tension homolog gene, confirming Cowden's syndrome. The patient died at age 29 due to neoplastic pathology.

Conclusion: This report aims to alert to the clinical signs of this entity and the clinical supervision and follow-up of these patients. In order to prevent premature deaths and to improve patient's quality of life, genetic diseases with cancer impact should be diagnosed as early as possible.
\end{abstract}

Keywords: Cowden's syndrome, PTEN, Papillary carcinoma, Breast sarcoma

\section{Background}

Cowden's syndrome (CS) was first described by Lloyd and Dennis in 1963, in a 20-year-old patient, Rachel Cowden, who had multiple deformations such as scrotal tongue syndrome, papillomatous papules, thyroid adenomas, fibrocystic breast disease with malignant degeneration, central nervous system changes, and family members with a mild form of the disease [1].

\footnotetext{
* Correspondence: sofiamiguelote@hotmail.com

${ }^{1}$ Faculty of Medicine, University of Porto, Porto, Portugal

Full list of author information is available at the end of the article
Only in 1996 was the susceptible zone of SC 10q22-23 mapped [2] and the tumor suppressor gene phosphatase and tension homolog (PTEN) that regulates the PI3K/Akt/ mTOR pathway was identified, which is responsible for the proliferation, migration, and cellular apoptosis [3].

PTEN hamartoma tumor syndrome (PHTS), which comprises CS, adult Lhermitte-Duclos disease (LDD), Bannayan-Riley-Ruvalcaba syndrome (BRRS), and Proteus-like syndrome, represents a spectrum of hamartomatous overgrowth manifestations associated with germline mutations in the PTEN gene [4].

(c) The Author(s). 2020 Open Access This article is licensed under a Creative Commons Attribution 4.0 International License, which permits use, sharing, adaptation, distribution and reproduction in any medium or format, as long as you give appropriate credit to the original author(s) and the source, provide a link to the Creative Commons licence, and indicate if changes were made. The images or other third party material in this article are included in the article's Creative Commons licence, unless indicated otherwise in a credit line to the material. If material is not included in the article's Creative Commons licence and your intended use is not permitted by statutory regulation or exceeds the permitted use, you will need to obtain permission directly from the copyright holder. To view a copy of this licence, visit http://creativecommons.org/licenses/by/4.0/ The Creative Commons Public Domain Dedication waiver (http://creativecommons.org/publicdomain/zero/1.0/) applies to the data made available in this article, unless otherwise stated in a credit line to the data. 
LDD is a rare, slow-growing hamartoma which is usually diagnosed when patients are in their twenties or thirties. While it appears to be clearly associated with PTEN mutations, the incidence of LDD in patients with CS is unknown. Vascular (venous or arterial) anomalies are reportedly common in BRRS and CS, particularly in patients with a BRRS diagnosis. A number of case reports support the association of arteriovenous malformations in clinically diagnosed BRRS patients [5].

It is important to recognize that in addition to LLD, other intracranial findings such as multiple venous anomalies, meningiomas, greater than expected white matter signal abnormality, prominent perivascular spaces, and cortical malformations may warrant a thorough evaluation for CS in the appropriate clinical setting $[6,7]$.

BRRS is typically diagnosed in childhood and is characterized by macrocephaly, hamartomas (including lipomas or intestinal polyps), penile freckling in males, and developmental delays, including an increased risk of autism spectrum disorder (ASD) [4]. Other reported features include developmental delay, vascular anomalies, large birth weight, and joint hyperextensibility [5].

CS is an autosomal dominant genodermatosis with variable expressiveness, with over 300 germline mutations in the PTEN gene already described but no significant correlation between mutation type and tumor types, and in $20 \%$ of the patients, no mutations were found [8]. Mucocutaneous lesions including trichilemmoma, acral keratosis, and oral papillomatosis, plus macrocephaly, are the most frequent features, described in more than $90 \%$ of cases after the third decade [9].

Multiple extra-mucocutaneous manifestations can also occur in CS. The skeletal system may form a higharched palate, scoliosis, or macrocephaly [10].

The estimated prevalence is $1 / 250,000$, with a slight predominance in females and Caucasians and penetrance of up to $90 \%$ in the second decade [11]. The diagnosis, normally, is based on clinical criteria, periodically updated by the National Comprehensive Cancer Network $^{\bullet}\left(\mathrm{NCNN}^{\bullet}\right)$ [12], though confirmatory genetic testing is frequently used.

\section{Case representation section}

The case being studied was reported at the São João Hospital, which is part of the Porto Medical School, University of Porto, in the North of Portugal.

Patient, female, Caucasian, born on 2 September 1989, having concluded year 9 and unemployed at the time.

Family history, mother with oligophrenia and maternal aunt died of thyroid carcinoma.

Personal history of childhood hydrocephalus, menarche at 12 years with irregular catamenia that have been corrected after the introduction of oral contraceptive. In 2008 , the patient was directed to psychiatry for suspected cognitive impairment.

In 2010, she had severe microcytic and hypochromic anemia and was treated with saccharized ferric oxide. Gynecological ultrasound without major changes and occult blood in the stool was negative. After hematological research, clinical research von Willebrand's disease was excluded.

In 2012, she was admitted to endocrinology due to changes in thyroid analytical parameters, TSH and $\mathrm{T}_{4}$ and $5-\mathrm{cm}$ thyroid nodule in the left lobe. An ultrasound was performed which identifies a 5.6-cm hypoechogenic nodule and anecogenic areas, the largest with $<1 \mathrm{~cm}$. Subsequently, she performed a fine-needle biopsy and was diagnosed with follicular lesion of undetermined significance (FLUS) (Bethesda category III). After a multidisciplinary meeting, it was decided to intervene the patient with total thyroidectomy.

In September 2012, she underwent $51 \mathrm{~g}$ total thyroidectomy and was diagnosed with papillary carcinoma solid/trabecular variant (Fig. 1). Concomitantly, she performs ablative therapy with $3700 \mathrm{MBq}(100 \mathrm{mCi})$ of $\mathrm{I}^{131}$ and is treated with levothyroxine and calcium.

In January 2013, research scintigraphy after 24-h oral administration of $18.5 \mathrm{MBq} \quad(50 \mathrm{mCi})$ of $\mathrm{I}^{131}$ was


Fig. 1 Solid/trabecular variant of papillary carcinoma. Well-defined tumor with trabecular pattern (a) composed by follicular cells with nuclear features of papillary carcinoma (b) and expression of TTF-1 (c) 



Fig. 2 a Right breast lump. b Radiological image of the breast lesion

conducted, revealing anterior cervical uptake focus compatible with functioning thyroid tissue and no other pathological fixation foci.

After 1 year, in routine ultrasound, microcalcifications were detected in the jugulocarotid chain, possibly related to a secondary injury to papillary thyroid carcinoma.

In November 2017, she was referred to the center of the breast by right breast lump in the upper left quadrant. At that time, she was 38 weeks pregnant and was being followed in obstetrics with a diagnosis of hydramnios, fetal hypothyroidism, and suspected fetal macrosomia opting for childbirth this week.

The breast ultrasound identified a well-circumscribed $3-\mathrm{cm}$ polylobular nodule classified as Breast ImagingReporting and Data System (BIRADS-2).

In May 2018, the breast ultrasound revealed a 4-cm nodular lesion and FNB was performed. The result revealed a heterogeneous mass of about $10 \mathrm{~cm}$ classifying as BIRADS-4C. Mammary computed tomography showed multilobulated contours with gross calcifications (Fig. 2).

In the histological study of the microbiopsy of the breast lesion, a malignant neoplasm compatible with high-grade sarcoma with areas of necrosis was observed. The neoplasm consists of spindle cells, atypical and with frequent figures of mitosis. The presence of osteosarcoma and rhabdomyosarcoma components is shown in Fig. 3.

It was proposed to the patient to undergo palliative right total mastectomy, and the recommended therapy was doxorubicin and ifosfamide. After explaining the precautions and warnings of the drugs, the patient chose to take doxorubicin only.

In August 2018, she performs bone scintigraphy revealing no image suggestive of focal metastatic and/or tumoral bone pathology with hyperfixation in right breast dependence compatible with heterotopic fixation by the breast lesion studied. For staging, she underwent computed tomography where nodules suggestive of metastases were found in the different lobes of both lung fields, all with a diameter less than $1 \mathrm{~cm}$ (Fig. 4).

Concomitantly, she was admitted for a genetic consultation, showing clinical macrocephaly $(58.1 \mathrm{~cm})$, round keratotic palmar pits, and wart vulgaris on the face and scalp (Fig. 5).

The genetic evaluation included the genes PTEN, TP53, BRCA1, BRCA2, ATM, CHEK2, and PALB2. $P T E N$ gene alteration was found. The result coincides with a change in heterozygote, pathogenic variant c.405dupA (p. (Cys136Metfs * 44) in the PTEN gene.
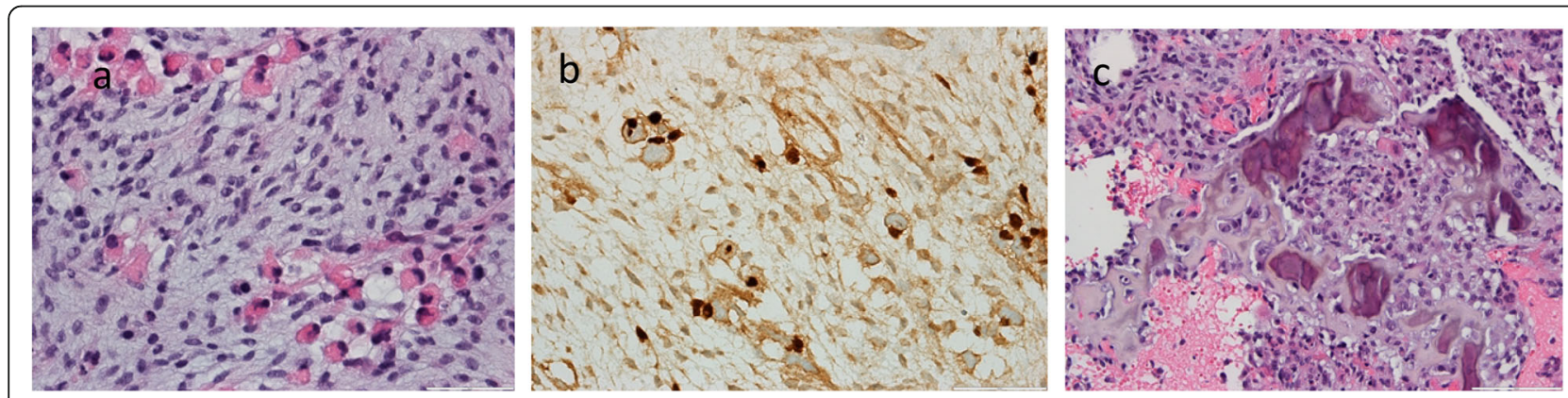

Fig. 3 High-grade sarcoma of the right breast composed by atypical spindle cells with rhabdomyoblastic (a, b) and osteosarcoma (c) components 

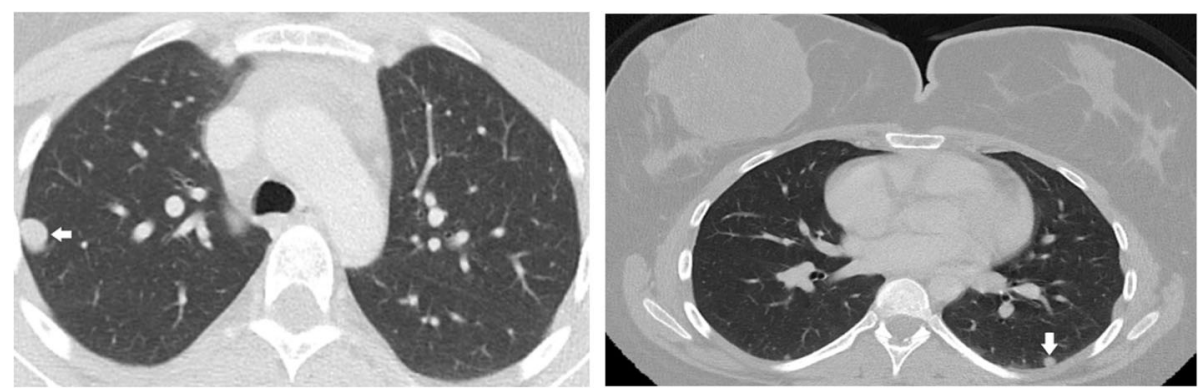

Fig. 4 Computed axial tomography with evidence of metastasis (white arrow)

This variant leads to the formation of a premature stop codon and potentially the appearance of a truncated protein.

She has 3 stepbrothers and 1 stepsister, but she has no relationship with them. The mother and uncles do not want to carry out the genetic test, and the siblings are unreachable. Genetic tests were not performed on the patient's limbs because they do not want to know.

In 2019, she died due to extensively metastatic breast cancer (Table 1). Since the diagnosis of papillary carcinoma at her death, only 11 years have passed, which demonstrates that the diagnosis made correctly and the time could have dictated another path.

\section{Discussion and conclusion}

CS presents itself with multiple hamartomas, and in 99\% of cases, its initial presentation is mucocutaneous lesions. These precede, by a few years, the neoplasms most at risk for this syndrome such as renal cell neoplasia and thyroid and breast carcinoma [13] (Table 2).

The importance of early diagnosis of this entity is related to the increase risk for certain cancers.

When the clinical phenotype raises suspicion, a screening test (https://www.lerner.ccf.org/gmi/ccscore/) can be carried out, which takes into account the individual's age and phenotype. In adults, a clinical threshold score of $\geq 10$ leads to a recommendation for referral to a genetics professional to consider PHTS. In children, macrocephaly and $\geq 1$ of the following leads to the consideration of PHTS: (1) autism or developmental delay; (2) dermatologic features, including lipomas, trichilemmomas, oral papillomas, or penile freckling; (3) vascular features, such as arteriovenous malformations or hemangiomas; and (4) gastrointestinal polyps [13].

The diagnosis is mostly clinical, and the diagnostic criteria created by Eng have been developed and are reviewed annually by the National Comprehensive Cancer Network ${ }^{\circ}\left(\mathrm{NCCN}^{\circ}\right)$ (Eng, 2000) (Table 3).

Confirmation of the diagnosis of CS is confirmed when it presents (Pilarsky, 2019):

1. Three or more major criteria, but one must include macrocephaly, LDD, or gastrointestinal hamartomas; or

2. Two major and three minor criteria.

When there is a family history of CS or PTEN mutation, CS is considered in the individual presenting (Pilarsky, 2019):

a) Two major criteria with or without minor criteria; or

b) One major criterion and two minor criteria; or

c) Three minor criteria.

The patient had several characteristic CS findings that satisfied three major criteria (macrocephaly, breast cancer, and mucocutaneous lesions) and two minor criteria (follicular variant of papillary thyroid cancer and intellectual disability), so she could be clinically diagnosed with CS.
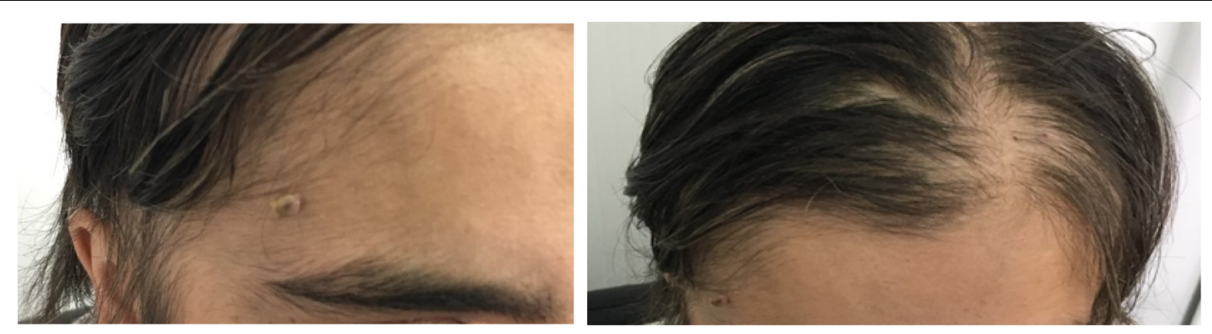

Fig. 5 Mucocutaneous lesion on the face and scalp 
Table 1 Clinical condition summary

\begin{tabular}{lll}
\hline ANO & Idade & DIAGNÓSTICO \\
\hline 2008 & 19 & Oligophrenia \\
2010 & 21 & Microcytic and hypochromic anemia \\
2012 & 23 & Papillary thyroid carcinoma \\
2017 & 28 & Breast sarcoma \\
2018 & 28 & Cowden's syndrome diagnose \\
2019 & 29 & Sarcoma metastasis \\
\hline
\end{tabular}

NCCN recommends, for woman, an annual mammography of tomosynthesis starting at age $30-35$ or 5-10 years before the earliest known breast cancer in the family. Given the $85 \%$ risk of developing breast cancer, the possibility of total mastectomy can be considered. Counseling should include a discussion regarding the degree of protection, reconstruction options, and risks. Because endometrial cancer can often be detected early based on symptoms, women should be educated regarding the importance of prompt reporting and evaluation of any abnormal uterine bleeding or postmenopausal bleeding. The evaluation of these symptoms should include endometrial biopsy every $1-2$ years.

For both, women and men, NCCN advocates annual thyroid ultrasound starting at the time of CS/PHTS diagnosis, including childhood, and colonoscopy starting at age 35 years unless symptomatic or if the close relative with colon cancer before age 40, then start 5-10 years before the earliest known colon cancer in the family. Colonoscopy should be done every 5 years or more frequently if the patient is symptomatic or polyps are found. Renal ultrasound should be considered starting at age 40 and then every 12 years. Dermatological evaluation and treatment may be necessary for some patients. Children should have a thorough psychomotor assessment, and brain symptoms should be assessed with magnetic resonance imaging.

The differential diagnosis of entities related to PTEN hamartoma must be considered. Some characteristics of CS are similar to BRRS, such as macrocephaly, gastrointestinal hamartomas, cognitive impairment, and pigmented macules on the penis. The mutational prevalence in PTEN

Table 2 Neoplasic risk and age of onset

\begin{tabular}{lll}
\hline Tumor & Risk to life (\%) & Beginning age \\
\hline Breast & 85 & 30 \\
Thyroid & 35 & $30-40$ \\
Kidney cells & 34 & 50 \\
Endometrium & 28 & $40-50$ \\
Gastrointestinal & 9 & 40 \\
Melanoma & 6 & 4 \\
\hline
\end{tabular}

Adapted

from https://rarediseases.org/rare-diseases/pten-hamartoma-tumor-syndrome/ Copyright@2019
Table 3 Diagnostic criteria for Cowden syndrome

\begin{tabular}{|c|c|}
\hline Criteria major & Criteria minor \\
\hline Breast cancer & Colon cancer \\
\hline Follicular thyroid cancer & $\begin{array}{l}\text { Esophageal glycogenic } \\
\text { acanthoses }(\geq 3)\end{array}$ \\
\hline Endometrial cancer & Lipomas ( $\geq 3$ ) \\
\hline Multiple gastrointestinal hamartomas & $\begin{array}{l}\text { Thyroid cancer (papillary or } \\
\text { follicular variant of papillary) }\end{array}$ \\
\hline Lhermitte-Duclos disease (adult) & Renal cell carcinoma \\
\hline Macrocephaly $(P \geq 97)$ & $\begin{array}{l}\text { Thyroid structural lesions (e.g. } \\
\text { adenoma, nodule(s), goiter) }\end{array}$ \\
\hline Macular pigmentation of glans penis & $\underline{\text { Intellectual disability }(\mathrm{Q} \mid \leq 75)}$ \\
\hline \multirow{3}{*}{$\begin{array}{l}\text { Mucocutaneous lesions: } \\
\text { - Trichilemmoma } \geq 3 \text { biopsy proven) } \\
\text { - Acral keratoses ( } \geq 3 \text { palmoplantar } \\
\text { keratotic pits and/or acral } \\
\frac{\text { hyperkeratotic papules) }}{\text { - Oral papillomas (particularly }} \\
\text { on tongue and gingiva), multiple } \\
(\geq 3) \text {, or biopsy-proven or } \\
\text { dermatologist-diagnosed } \\
\text { mucocutaneous neuromas } \\
\geq 3 \text { ) }\end{array}$} & Autism spectrum disorder \\
\hline & Testicular lipomatosis \\
\hline & $\begin{array}{l}\text { Vascular anomalies (including } \\
\text { multiple intracranial } \\
\text { developmental venous } \\
\text { anomalies) }\end{array}$ \\
\hline
\end{tabular}

Adapted from https://www.nccn.org Copyright@2019

is around 60\%; however, specific diagnostic criteria for this entity have not yet been crated. Regarding LDD, in which the prevalence of the affected PTEN is around $83 \%$, the clinical findings are fundamentally based on slowly growing hamartoma of the cerebellum and usually diagnosed when patients are in their twenties or thirties [5].

When the trio of thyroid, breast, and renal cell carcinoma arises, not only the PTEN gene but also the $S D H B$ / $C / D$ gene should be screened [10].

The clinical evaluation and follow-up of these patients should be thorough so that the evolution of certain malignancies is detected in a timely manner and their diagnosis and treatment as appropriate as possible.

When diagnosed, patients should be instructed to be aware of the signs and symptoms of cancers with a higher incidence in this disease. Sirolimus is in phase II for PHTS and other drugs are being studied for solid neoplasms in individuals with CS that act on the pathway PI3K/akt/mTOR (BGT226 and BEZ235 in phase II).

\section{Abbreviations}

CS: Cowden's syndrome; PTEN: Phosphatase and tension homolog; LLD: Lhermitte-Duclos disease; BRRS: Bannayan-Riley-Ruvalcaba syndrome; BIRADS: Breast Imaging-Reporting and Data System

\section{Acknowledgements \\ Not applicable}

\section{Authors' contributions}

$\mathrm{SM}$ was the main contributor to the writing of the manuscript. RH performed the histological examination of the thyroid and breast. LF provided some patient data and images. LE analyzed and interpreted the patient data. JAT is the first author's advisor for the elaboration of the master's thesis in medicine. The authors read and approved the final manuscript. 


\section{Funding}

No financial sources.

\section{Availability of data and materials}

The datasets generated and analyzed during the current study are not publicly available due to belonging to the clinical entity (São João University Hospital

Center) but are available from the corresponding author on reasonable request.

\section{Ethics approval and consent to participate}

All clinical information, whether imaging or histological, was provided by the bioethics department of the University Hospital Center of S. João for the elaboration of the master's thesis in medicine. The respective authorizations of the hospital ethics committee are in the supplement.

\section{Consent for publication}

Informed consent was provided by the patient's hospital.

\section{Competing interests}

The authors declare that they have no competing interest.

\section{Author details}

${ }^{1}$ Faculty of Medicine, University of Porto, Porto, Portugal. ${ }^{2}$ University Hospital Center of S. João, Porto, Portugal. ${ }^{3}$ Pathological Anatomy Department, University Hospital Center of S. João, Porto, Portugal. ${ }^{4}$ Breast Center, University Hospital Center of S. João, Porto, Portugal. ${ }^{5}$ Surgery Department, University Hospital Center of S. João, Porto, Portugal.

Received: 30 March 2020 Accepted: 28 July 2020

Published online: 17 August 2020

\section{References}

1. Yehia L \& Eng. One gene, many endocrine and metabolic syndromes: PTENopathies and precision medicine. Endocrine Related Cancer 25 121-140, 2018.

2. Nelen MR, Padberg GW, Peeters EA, Lin AY, van den Helm B, Frants RR, Coulon V, Goldstein AM, Van Reen MM, Easton DF, et al. Localization of the gene for Cowden disease to chromosome 10q22-23. Nature Genetics. 1996;13:114-6.

3. Shenandoah R, Alan RC. Cowden disease and Lhermitte-Duclos disease: an update. Case report and review of the literature. Neurosurg Focus. 2016;20(1):E6.

4. Ueno Y, Enokizono H, Ohto T, Imagawa K, Tanaka M, Sakai A, Suzuki H, Uehara T, Takenouchi T, Kosaki K, Takada H. A novel missense PTEN mutation identified in a patient with macrocephaly and developmental delay. Human Genome Variation 6:25, 2019.

5. Pilarski R. PTEN hamartoma tumor syndrome: a clinical overview. Division of Human Genetics, Department of Internal Medicine and Comprehensive Cancer Center, Ohio State University, Columbus, OH 43221, USA. 2019.

6. Dhamija R, Weindling SM, Porter AB, Hu LS, Wood CP. Hoxworth. Neuroimaging abnormalities in patients with Cowden syndrome: retrospective single-center study. Neurol Clin Pract. 2018

7. Kimura F, Ueda A, Sato E, Akimoto J, Kaise H, Yamada K, Hosonaga M, Kawai Y, Teraoka S, Okazaki M, Ishikawa T. Hereditary breast cancer associated with Cowden syndrome - related PTEN mutation with Lhermitte-Duclos disease, Surgical Case Report, 2017.

8. Porto AC, Roider E, Ruzicka T. Cowden syndrome: report of a case and brief review of literature. An Bras Dermatol. Nov-Dec; 88(6 Suppl 1):52-55, 2013.

9. Cavaillé M, Ponelle-Chachuat F, Uhrhammer N, Viala S, Gay-Bellile M, Privat M, Bidet $Y$, Bignon $Y$. Early onset multiple primary tumors in atypical presentation of Cowden syndrome identified by whole-exome-sequencing. Front Genet. 2018.

10. Garofola C, Gross G. Cowden disease (multiple hamartoma syndrome): NCBI Bookshelf; 2019.

11. Farooq A, Walker LJ, Bowling J, Audisio RA (2010) Cowden syndrome. Cancer Treat Rev 36: 577-583.

12. National Comprehensive Cancer Network (NCCN). Cowden syndrome/PTEN hamartoma tumor syndrome (2018).

13. Eng C. PTEN hamartoma tumor syndrome (PHTS) - GeneReviews, 2001, Updated 2016

\section{Publisher's Note}

Springer Nature remains neutral with regard to jurisdictional claims in published maps and institutional affiliations.

\section{Ready to submit your research? Choose BMC and benefit from:}

- fast, convenient online submission

- thorough peer review by experienced researchers in your field

- rapid publication on acceptance

- support for research data, including large and complex data types

- gold Open Access which fosters wider collaboration and increased citations

- maximum visibility for your research: over $100 \mathrm{M}$ website views per year

At $\mathrm{BMC}$, research is always in progress.

Learn more biomedcentral.com/submissions 